\title{
Correction to: Current status of ctDNA in precision oncology for hepatocellular carcinoma
}

Yan $\mathrm{Li}^{1,2}$, Yuanyuan Zheng ${ }^{2}$, Liwei $\mathrm{Wu}^{2}$, Jingjing $\mathrm{Li}^{1,2}$, Jie Ji ${ }^{2}$, Qiang $\mathrm{Yu}^{2}$, Weiqi Dai ${ }^{1,2}$, Jiao Feng ${ }^{2^{*}}$, Jianye Wu ${ }^{1 *}$ and Chuanyong Guo ${ }^{1,2^{*}}$ (D)

\section{Correction to: J Exp Clin Cancer Res 40, 140 (2021) https://doi.org/10.1186/s13046-021-01940-8}

Following publication of the original article [1], the authors identified an error in the author affiliations. Chuanyong Guo's first affiliation was missing; Chuanyong Guo's affiliations are therefore:

${ }^{1}$ Department of Gastroenterology, Putuo People's Hospital, Tongji University School of Medicine, number 1291, Jiangning road, Putuo, Shanghai, 200060, China

${ }^{2}$ Department of Gastroenterology, Shanghai Tenth People's Hospital, Tongji University School of Medicine, Number 301, Middle Yanchang road, Jing'an, Shanghai 200072, China

The original article has been corrected.

Published online: 13 July 2021

\section{Reference}

1. Li Y, Zheng Y, Wu L, Li J, Ji J, Yu Q, et al. Current status of ctDNA in precision oncology for hepatocellular carcinoma. J Exp Clin Cancer Res. 2021;40:140 https://doi.org/10.1186/s13046-021-01940-8.

The original article can be found online at https://doi.org/10.1186/s13046021-01940-8,

* Correspondence: fengjia0080801@163.com; wjymail@163.com; guochuanyong@hotmail.com

'Department of Gastroenterology, Putuo People's Hospital, Tongji University School of Medicine, number 1291, Jiangning road, Putuo, Shanghai 200060, China

${ }^{2}$ Department of Gastroenterology, Shanghai Tenth People's Hospital, Tongji University School of Medicine, Number 301, Middle Yanchang road, Jing'an, Shanghai 200072, China

(c) The Author(s). 2021 Open Access This article is licensed under a Creative Commons Attribution 4.0 International License, which permits use, sharing, adaptation, distribution and reproduction in any medium or format, as long as you give appropriate credit to the original author(s) and the source, provide a link to the Creative Commons licence, and indicate if changes were made. The images or other third party material in this article are included in the article's Creative Commons licence, unless indicated otherwise in a credit line to the material. If material is not included in the article's Creative Commons licence and your intended use is not permitted by statutory regulation or exceeds the permitted use, you will need to obtain permission directly from the copyright holder. To view a copy of this licence, visit http://creativecommons.org/licenses/by/4.0/. The Creative Commons Public Domain Dedication waiver (http://creativecommons.org/publicdomain/zero/1.0/) applies to the data made available in this article, unless otherwise stated in a credit line to the data. 